\title{
Laboreal
}

Volume 11 №2 | 2015

Varia

\section{O desenvolvimento de competências na atividade coletiva de trabalho dos enfermeiros}

El desarrollo de las habilidades en la actividad colectiva del trabajo de los enfermeros

Le développement de compétences dans l'activité collective de travail des infirmiers

The development of competences in the collective activity of the nurse work

Isabel Freitas

\section{CpenEdition}

Journals

Edição electrónica

URL: http://journals.openedition.org/laboreal/3701

DOI: 10.4000/laboreal.3701

ISSN: 1646-5237

\section{Editora}

Universidade do Porto

\section{Refêrencia eletrónica}

Isabel Freitas, «O desenvolvimento de competências na atividade coletiva de trabalho dos enfermeiros », Laboreal [Online], Volume 11 №2 | 2015, posto online no dia 01 dezembro 2015 consultado o 07 outubro 2019. URL : http://journals.openedition.org/laboreal/3701 ; DOI : 10.4000/ laboreal.3701

Este documento foi criado de forma automática no dia 7 outubro 2019.

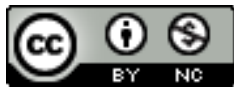

Laboreal está licenciado com uma Licença Creative Commons - Atribuição-NãoComercial 4.0 Internacional. 


\section{O desenvolvimento de competências na atividade coletiva de trabalho dos enfermeiros}

El desarrollo de las habilidades en la actividad colectiva del trabajo de los enfermeros

Le développement de compétences dans l'activité collective de travail des infirmiers

The development of competences in the collective activity of the nurse work

Isabel Freitas

\section{NOTA DO EDITOR}

http://dx.doi.org/10.15667/laborealxi0215if

Manuscrito recebido em: junho/2015

Aceite após peritagem: novembro/2015

\section{1- Introdução}

1 O estudo que apresentamos foi realizado no Serviço de Cirurgia Geral de um Hospital Público português e o seu objetivo inicial foi descrever o trabalho real dos enfermeiros: as estratégias desenvolvidas para realizar as tarefas, diversificadas e em constante interação, num contexto complexo e mutável. Algumas tentativas para descrever as tarefas do enfermeiro haviam surgido em 1994 com o objetivo de estabelecer padrões de qualidade no trabalho de enfermagem nas quais os enfermeiros não reviam a sua atividade. Tornou-se, assim, evidente a dificuldade de avaliar a qualidade e a importância do estudo da atividade do enfermeiro na sua interação com um contexto particular. $\mathrm{O}$ estudo iniciou-se sem qualquer pedido por parte da Direção do Hospital 
mas ao longo da sua realização fomos obtendo a colaboração dos enfermeiros, a sua disponibilidade e o seu enorme entusiamo para comentar e explicar a atividade, as dificuldades sentidas, os problemas encontrados e as soluções parciais para os resolver, as propostas para melhorar a realização do trabalho, os conhecimentos utilizados. Durante aproximadamente 2 anos permanecemos quase diariamente no Hospital e participamos na experiência de trabalho dos enfermeiros, observamos a realização da atividade e efetuamos pequenas entrevistas durante a sua realização. Esta interação diária com os enfermeiros foi fundamental na nossa reflexão teórica que partiu de questões de Psicologia Cognitiva fundamentais para aprofundar duas características do trabalho do enfermeiro: a complexidade e a dinâmica. O quadro teórico apoiou-se numa abordagem cognitiva das competências, não dominante em Psicologia, defendida por vários autores (Fischer \& Bidell, 2006; Pinsky \& Theureau, 1982; Weill-Fassina, 1993): a competência é uma organização atual, uma ação intencional e organizada num contexto específico favorecendo o desenvolvimento, não linear e não determinado. Assim, é possível explicar porque é que o trabalhador põe em prática diversos saberes e saberes-fazer na realização de uma tarefa em diferentes contextos, manifestações da competência, assim como a sua progressiva organização em níveis de concetualização mais abstratos. Através da nossa abordagem empírica pretendemos ilustrar o quadro teórico de que partimos, particularmente a hipótese desenvolvimental de uma continuidade e complementaridade entre as perspetivas macro e microgenética sobre a formação de competências. A articulação das duas perspetivas possibilitou uma primeira abordagem do desenvolvimento do saber na e para a ação no contexto do trabalho de enfermagem: como é que o conhecimento organizado por e para uma determinada situação evolui ao longo da vida profissional? As experiências vividas possibilitam o controlo da ação que se torna mais eficaz e ajustada às situações? As experiências vividas proporcionam uma outra leitura da ação em situação? O saber, organizado por e para uma situação concreta, torna-se mais abstrato e menos dependente das situações concretas no decorrer da vida profissional? a ação, mais ajustada às características da situação integra a imprevisibilidade das situações? Como podemos caracterizar a gestão da imprevisibilidade na planificação?

2 Foram estas interrogações teóricas que orientaram a segunda fase do nosso estudo, após os dois anos iniciais, durante a qual realizamos registos áudio visuais da passagem de turno utilizados posteriormente em situação de simulação da passagem de turno. Esta metodologia possibilitou uma abordagem mais precisa e sistemática da atividade do enfermeiro e uma primeira proposta de formalização das estratégias de prestação de cuidados e registos de funcionamento no planeamento das ações de prestação de cuidados. O estudo que apresentamos é uma tentativa de descrever, de forma necessariamente sintética, o trabalho de investigação realizado.

\section{2 - A transformação da competência: adaptação a um contexto ou construção de novas competências e contextos?}

3 A conceção da competência como estrutura supõe a formação e a transformação da competência através da ação num processo de apropriação. Esta perspetiva, já presente nos trabalhos de Piaget (1975), levanta questões fundamentais e gerais sobre a interdependência da ação e do conhecimento: o conhecimento e o ato de conhecer são 
separados? Os significados são construídos na atividade de conhecer? Qual o papel do contexto na atividade de conhecer?

Na Psicologia do Trabalho estas questões são debatidas nomeadamente nos estudos realizados no âmbito da Ergonomia da Atividade. Na discussão os autores interrogam-se sobre a noção de competência: ação intencional e organizada num contexto ou ação atualizada num contexto?

As duas abordagens distinguem-se na forma como concebem a cognição: a cognição é o conhecimento? o conhecimento e a representação são distintos? O conhecimento é independente da experiência do sujeito e a representação depende da experiência? Ou o conhecimento e a representação coincidem e o sujeito constrói os seus conhecimentos e representações através da sua experiência. Neste último caso, o conhecimento e as atividades de conhecer não são separados e existe, por isso, uma relação entre conhecimento e experiência, perspetiva defendida por Weill-Fassina (1993). Para a autora o conhecimento e o ato de conhecer é uma construção permanente do mundo conduzindo este debate a uma outra interrogação: os significados, a intencionalidade é construída no contexto da ação ou ela é predefinida e, sendo assim, a ação é pré organizada? Pinsky e Theureau (1982) distinguiram o processo de construção de significados em situação do processo de tratamento da informação propondo a noção cours d'action para a análise da atividade. Os autores salientaram a importância das relações que o trabalhador constrói, no decurso da atividade, entre ações, comunicações e interpretações organizando permanentemente a sua ação. $O$ coletivo de trabalho e o contexto social são fundamentais na formação da competência sendo o processo de formação da competência mais do que uma simples adaptação ao meio social. O processo de formação é, também, a criação de um novo contexto social e a criação de novos sentidos e novas relações nesse meio.

6 Strauss, Schatzman, Bucher, Ehrlich e Sabshin (1992) nos estudos que conduziram em contexto hospitalar salientaram que no funcionamento de um hospital existe um espaço de contingência negociado através de relações intersubjetivas que evoluem no tempo. Para Clot (1995), este espaço de troca interpsíquica das atividades estaria na origem de um trabalho intrapsíquico, e estas passagens do coletivo ao individual seriam fundamentais para compreender como é que a atividade pode ser desenvolvida e como é que novas competências se formam. Inspirado na obra de Vygotsky $(1934,1996)$, Clot (1995) propôs a noção de desenvolvimento potencial para explicar que na realização do trabalho existe um espaço potencial de ação que é utilizado pelo trabalhador para atribuir novos significados às atividades e construir, assim, novas competências.

7 Os estudos empíricos, realizados no domínio da Ergonomia da Atividade, sobre a cooperação e a comunicação no trabalho, ilustraram como é que determinadas práticas coletivas no trabalho favorecem a apropriação do real, o movimento do trabalhador na sua zona de desenvolvimento potencial (Clot, 1995) e em consequência a construção de novas competências. Por exemplo, Grusenemyer (1996), Cahour e Salembier (1995), Falzon (1989), estudaram a cooperação através da análise da comunicação no grupo de trabalho. Nesta perspetiva a comunicação é considerada um ato de linguagem (Searle, 1979), um ato com uma intencionalidade que supõe a transformação do locutor, a transformação do interlocutor e das suas relações. Grusenemyer (1996) evidenciou os processos de ajustamento e a construção de representações funcionais partilhadas através da análise dos diálogos de trabalhadores durante a passagem de turno. Cahour e Salembier (1995), Falzon (1989) salientaram, nos diálogos entre peritos e principiantes, 
a construção de um modelo do interlocutor, os seus objetivos e conhecimentos, e as dificuldades e os erros de diagnóstico que surgem quando cada uma das partes não possui uma representação da outra.

8 Esta atividade de ajustamento e de cooperação é um processo de transformação horizontal da estrutura dos conhecimentos para a ação, existe transformação da competência no sentido da variabilidade. Este processo é acompanhado por um outro através do qual ocorrem transformações, da estrutura dos conhecimentos, no sentido da abstração.

\section{3 - 0 desenvolvimento de competências: a perspetiva macrogenética e microgenética}

9 Se articularmos a abordagem apresentada sobre o conhecimento e a representação e a sua construção através da ação intencional em situação, ilustrada através de alguns estudos empíricos realizados no domínio da Ergonomia da Atividade, com as questões sobre os processos de formação das competências, compreendemos a transformação das competências não só na sua variabilidade mas também do ponto de vista do seu desenvolvimento. A formação de competências ocorre através da interdependência de dois processos: o processo microgenético e o processo macrogenético (Weill-Fassina, 1993). Neste mesmo sentido e mais recentemente, Pastré (2007) salientou duas dimensões da atividade - produtiva e construtiva. Apesar de distintas, as duas dimensões são inseparáveis combinando conhecimentos organizados e desenvolvidos ao longo da vida profissional (dimensão produtiva) com conhecimentos sobre a atividade desempenhada pelo trabalhador num momento e contexto especifico (dimensão construtiva). A articulação das duas dimensões possibilita a reconstrução dos saberes profissionais e das situações de trabalho.

$\mathrm{Na}$ explicação microgenética é fundamental a tese funcionalista da teoria de Piaget (1975) sobre a transformação das estruturas cognitivas. O processo microgenético revela como é que os conhecimentos e as representações se transformam em períodos de tempo muito curtos e no decurso da atividade. Neste processo salienta-se o papel ativo do trabalhador, o seu funcionamento adaptativo em contextos muito específicos, instáveis e povoados de acontecimentos inéditos (Pastré, 2011). Nestes contextos, o conhecimento torna-se generalizado e diferenciado e, assim, temos uma contribuição importante para esclarecer a aparente incongruência das duas características da competência: a competência é particular a um contexto e simultaneamente pode ser aplicada em situações diversas. Porque a transferência não se reduz a um processo de generalização do qual resultam invariantes, a transferência implica processos de descontextualização mas também de recontextualização das invariantes (Roussel, 2011). Como consequência, a organização da ação é caracterizada por uma maior distância relativamente às situações concretas e pela compreensão do "porquê não se faz de outro modo" (Samurçay \& Pastré, 1998, p. 108). Os conhecimentos são organizados em classes de situações mais ricas que incorporam a variabilidade das situações. A compreensão do "porquê não se faz de outro modo" revela a diferenciação do conhecimento, o seu ajustamento nas situações concretas. Compreende-se o que distingue as diversas situações, condições e constrangimentos e, em consequência, utiliza-se o conhecimento mais ajustado à especificidade de cada situação. Estas características são frequentemente observadas na realização de tarefas por peritos. Por 
exemplo, estudos que comparam os menos experientes com os mais experientes na realização de uma tarefa mostram que, os trabalhadores menos experientes prestam pouca atenção à especificidade das situações, às variações e aos imprevistos no trabalho (Delgoulet, 2015). Nos menos experientes verifica-se, também, um acesso menos rápido aos conhecimentos e os seus raciocínios são caracterizados por um baixo nível de abstração, baseiam-se nos traços de superfície das situações e são muito dependentes das condições de trabalho em que se encontram (Delgoulet, 2015). Segundo WeillFassina (2010), os mais experientes integram um número cada vez maior de elementos da situação progressivamente menos confundidos e dependentes da ação concreta.

11 O processo macrogenético descreve os vários patamares, estruturas, na formação do conhecimento durante longos períodos de tempo, ao longo da vida profissional. Tratase de um processo de controlo da ação que implica a conceptualização ao longo da vida profissional sendo fundamental o contexto. O contexto de trabalho (regras, instrumentos, colegas, chefes, clientes) estabelece objetivos a atingir, constrangimentos a contornar, regras a seguir, proporciona a partilha de conhecimentos com os outros, etc. Neste processo, o controlo da ação é um processo de ajustamento criativo ao contexto de trabalho, um processo de confronto e compromisso entre decisões, ações e a observação dos seus efeitos e, em consequência, é um processo de transformação das tarefas no sentido da sua realização eficaz.

\section{4 - 0 terreno do estudo}

\subsection{Caracterização do Serviço de Cirurgia Geral}

O Serviço de Cirurgia Geral está integrado num Hospital Público constituído por 17 Serviços: três Serviços de Cirurgia Geral e um Serviço de Especialidades Cirúrgicas (os 4 Serviços pertencem ao Departamento de Cirurgia), três Serviços de Medicina, dois Serviços de Ortopedia, um Serviço de Pediatria, um Serviço de Neonatologia, um Serviço de Consulta Externa, um Serviço de Obstetrícia e Ginecologia, Unidade de Cuidados Intensivos, Bloco Operatório, Urgência e Esterilização. O Serviço de Cirurgia Geral assegura os cuidados e tratamentos pós cirúrgicos a doentes submetidos a cirurgias gerais (tubo digestivo, mama, tiroide e vascular venosa) programadas ou de urgência. Podem ainda ser prestados cuidados e tratamentos necessários ao estabelecimento de um diagnóstico médico, habitualmente designados de doentes para estudo. 0 período de internamento dos doentes é, em média de 8,2 dias. A equipa de saúde é constituída por um diretor de departamento, cinco médicos, um enfermeiro chefe, 21 enfermeiros, 8 auxiliares de ação médica e é apoiada por um secretário de unidade (comum aos 4 serviços de cirurgia). o Serviço de Cirurgia Geral dispõe de uma capacidade máxima de internamento de 34 doentes, as 34 camas estão distribuídas por 10 enfermarias de 3 camas cada uma e quatro quartos individuais (isolamentos)

\subsection{A qualidade}

13 No período em que decorreu o estudo, o processo de acreditação para a prestação de cuidados com qualidade era um tema ainda embrionário no Serviço de Cirurgia Geral em estudo. A preocupação com a qualidade na prestação dos cuidados encontrava-se na prática diária dos enfermeiros, principalmente na forma como o trabalho é organizado. 
Vários atores ligados à prestação de cuidados (enfermeiros do serviço, enfermeiros professores orientadores dos estágios de enfermagem no serviço, alunos de enfermagem) e responsáveis do Hospital envolviam-se em discussões sobre a qualidade e a humanização dos cuidados de enfermagem e de saúde. Esta preocupação tornou-se manifesta ao nível das práticas a partir de 1994, período no qual se passou de uma prestação de cuidados à tarefa para uma prestação de cuidados pelo método individual. Segundo os vários intervenientes, esta transformação na forma de organizar o trabalho permitia criar relações de maior proximidade entre o enfermeiro e o doente e o melhor aproveitamento dos recursos da instituição. Na realidade, as transformações na organização do trabalho tiveram um impacto importante principalmente ao nível da colaboração entre enfermeiros tornando a sua atividade mais conceptual. Passou-se de situações de colaboração (Savoyant, 1984) nas quais são partilhadas tarefas prescritas para o mesmo doente, a situações de cooperação distribuída (Rogalsky, 1994). Nesta nova fase, os enfermeiros colaboram desempenhando individualmente tarefas de prestação de cuidados ao mesmo doente, em turnos diferentes, e participam, deste modo, na realização de uma tarefa com um objetivo comum mais global - a manutenção de um padrão de saúde de um doente. Uma importante caraterística na nova forma de colaboração é que múltiplas pessoas participam na realização de objetivos mais globais e, por isso, a discussão sobre os cuidados a prestar ao mesmo doente, nos diversos turnos, torna-se fundamental. Estas relações de cooperação distribuída são apoiadas por práticas de trabalho reconhecidas, por exemplo a passagem de turno. Neste contexto de valorização dos conhecimentos e da prática de enfermagem, decorria, simultaneamente, no hospital um estudo sobre a qualidade dos cuidados de enfermagem, sob a orientação da Direção Geral dos Hospitais e integrado num programa de cooperação com a Organização Mundial de Saúde. 0 estudo procurava implementar uma metodologia e um modelo para a atividade do enfermeiro. A metodologia, o processo de enfermagem, propõe quatro etapas lógicas sucessivas na prestação de cuidados com qualidade (identificação de problemas de enfermagem, planeamento, execução e avaliação dos cuidados de enfermagem), salientando-se a importância dos conhecimentos de enfermagem em cada etapa (o modelo). Mas a metodologia e o modelo propostos encontravam vários obstáculos para a sua implementação e as principais razões relacionavam-se com a necessidade de redefinir os problemas de enfermagem, colocando importantes questões ao nível dos conhecimentos de enfermagem aprendidos na escola, reorganização das tarefas de enfermagem no hospital e da relação dos enfermeiros com outros profissionais de saúde e com o coletivo mais amplo do hospital. Salienta-se a importância da recolha de dados sobre os contextos da atividade e é prevista uma forma lógica de lidar com os problemas humanos, no entanto não é considerada a possibilidade de construção dos significados e do sentido da atividade na interação com o contexto. Como vários enfermeiros o afirmam "quando utilizamos o processo de enfermagem voltamos à escola" porque a atividade do enfermeiro não se limita a um conjunto de etapas de raciocínio aplicáveis a situações predefinidas, visíveis e lógicas. A atividade é uma construção única que concilia o rigor dos conhecimentos e do raciocínio, características do processo de enfermagem, com a pertinência do significado da ação em situação. É esta construção que muitos enfermeiros pretendiam ver desenvolvida na passagem de turno e noutras práticas de enfermagem através de relações de cooperação distribuída mas que, por motivos ligados à escassez de recursos (por exemplo, falta de pessoal) e reduzida influência da enfermagem no funcionamento do hospital, acabam por ser 
pouco valorizadas e, em parte, substituídas por práticas mais burocráticas na organização da prestação de cuidados. São estas práticas na passagem de turno que procuramos descrever em 4.3.. Em síntese, as transformações na organização do trabalho tornaram a atividade do enfermeiro mais conceptual e, simultaneamente, a implementação de uma abordagem lógica, técnica e predefinida dos cuidados contribuiu para fechar o enfermeiro num conjunto de receitas e procedimentos com pouco sentido para a sua prática. Foi neste contexto que iniciamos o nosso estudo de descrição do trabalho do enfermeiro, procurando salientar duas características: a complexidade e a dinâmica.

\subsection{0 trabalho do enfermeiro: um trabalho complexo e dinâmico}

14 O trabalho diário do enfermeiro tem duas fases distintas, a prestação de cuidados e a passagem de turno. A prestação de cuidados obedece às normas próprias do hospital e do serviço, às rotinas e protocolos. As rotinas, "o que se faz todos os dias, com tempos marcados e atividades marcadas", são mais frequentes no turno da manhã que se inicia com a prestação de cuidados especiais (avaliação de temperatura, glicemia, etc.) seguindo-se a prestação de cuidados de higiene e administração da medicação, realização de pensos, administração da medicação, posicionamentos e termina com o registo escrito de alterações nos processos do doente. Os protocolos são criados pelos enfermeiros e, nalguns casos, são negociados com a equipa médica, estabelecem os procedimentos a seguir em determinadas situações, as condições para a sua aplicação (quando e em que circunstâncias) e os limites de atuação dos enfermeiros. O conhecimento dos protocolos é mobilizado nas situações de rotina ou na procura de respostas e soluções para as situações inesperadas relacionadas quer com o estado do doente quer com acontecimentos do serviço (por exemplo, se o doente tem dor o enfermeiro pode administrar um analgésico).

15 A passagem de turno é um período de encontro entre os enfermeiros que terminam o turno de trabalho e os enfermeiros que iniciam o novo turno. Tem uma duração aproximada de trinta minutos e realiza-se três vezes por dia: passagem de turno das $8 \mathrm{~h}$, passagem de turno das $16 \mathrm{~h}$ e passagem de turno das $24 \mathrm{~h}$. O objetivo deste período de trabalho é a transmissão e discussão das informações relativas aos doentes, funcionamento do Serviço e Hospital. Estas informações são apresentadas oralmente pelo enfermeiro que termina o turno de trabalho. No entanto, devido principalmente à duração deste momento, trinta minutos para transmitir informação relativa a trinta e quatro doentes, a passagem de turno acaba por se reduzir, frequentemente, à transmissão de informação. Os cuidados prestados e a prestar raramente são objeto de discussão e a transmissão de informação tem uma função fundamental: coordenar as ações entre os vários elementos da equipa de saúde que prestam cuidados nos diferentes turnos assegurando-se a qualidade dos cuidados. A passagem de turno apoiase em diferentes informações:

16 - registos escritos que descrevem a evolução do estado do doente desde o inicio do internamento - o processo do doente; o processo do doente inclui, entre outros registos, as notas de enfermagem que, para alguns doentes, escolhidos aleatoriamente pelos enfermeiros, são organizadas segundo o processo de enfermagem;

17 - registos escritos que fornecem uma visão rápida, global e sintética do estado do doente durante um turno, atualizada em todos os turnos (plano coletivo de cuidados); 
18 As notas de enfermagem são, em conjunto com o plano coletivo de cuidados, um dos principais meios de comunicação dentro da equipa de enfermagem e com a equipa de saúde (médicos e auxiliares de ação médica).

Durante o turno, os enfermeiros procuram seguir o plano que cada um estabelece durante a passagem de turno mas esta organização pode ser posta em causa por acontecimentos imprevistos que exigem um ajustamento constante da atividade à evolução do estado do doente e às ações dos outros elementos da equipa de saúde. Principalmente no turno da manhã numerosos imprevistos surgem e perturbam o plano inicial sendo os mais frequentes as altas médicas não previstas, as entradas não programadas para cirurgias, que implicam um conjunto de tarefas administrativas e ocupam uma grande parte do tempo de trabalho (preenchimento de papéis, contato com as famílias, informação do doente, etc.) e a vigilância das alterações do estado do doente. Como refere uma enfermeira:

\footnotetext{
"Por vezes planeamos muitas coisas, às vezes planeamos e executamos ao mesmo tempo e outras vezes fazemos planeamentos encadeados, estamos a pensar uma coisa e surge outra para fazer, temos de estar sempre a fazer isto senão perde-se muito tempo e não conseguimos fazer tudo".
}

Por isso a atividade do enfermeiro é complexa e dinâmica (Hoc, 1996). Complexa porque obriga num determinado momento a considerar múltiplos elementos, em interação, para avaliar o estado do doente e agir. É assim que uma enfermeira que regressa ao serviço depois de três folgas consecutivas, comenta, no fim da passagem de turno, as atividades de prestação de cuidados que vai iniciar:

"Não conheço os doentes e os colegas não os apresentaram durante a passagem de turno, por isso estou a ver os diagnósticos, os cuidados iniciais, o que foi feito ontem, como se alimentaram para poder planear o que vou fazer e conhecer melhor os meus doentes".

21 Os dados que o enfermeiro dispõe para avaliar, estabelecer objetivos, realizar intervenções, são inseridos num contexto institucional, na história passada e atual do doente que raramente apresenta um único problema mas uma multiplicidade de problemas que interagem e resultam num sinal, num sintoma específico, numa queixa que, também, evolui no tempo, obrigando a um complicado trabalho de articulação. A articulação com outros Serviços do Hospital não é fácil, cada um tem as suas regras de funcionamento (horários, procedimentos, registos de enfermagem, uma linguagem própria, etc.) obrigando a um complicado trabalho de articulação. Uma enfermeira comenta do seguinte modo o problema de um doente que acaba de entrar no Serviço, enviado pelo Serviço de Urgência:

\footnotetext{
"Eu conheço este doente, esteve internado em Setembro aqui e conheço os seus problemas sociais. Sei que entrou com uma úlcera duodenal no Serviço de Urgência e eu tenho de falar com o marido, vigiar as perdas hemáticas, ela tem prescrição de entubação nasogástrica, mas não percebo nas notas de enfermagem da urgência se esteve entubada e retirou, se não esteve entubada, não percebo o que se passou, tenho de falar com os meus colegas (do serviço de urgência)".
}

Por isso, a atividade também é dinâmica, o estado do doente evolui continuamente em parte, de forma espontânea e, em parte, dependente das ações de enfermagem, ou outras, que sobre ele são exercidas. 0 enfermeiro enfrenta, assim, a imprevisibilidade 
dos efeitos das ações próprias e dos outros, da evolução do estado do doente e da sua combinação.

Estas características da atividade justificam o estudo da planificação da ação, realizada durante a passagem de turno, segundo a perspetiva macrogenética e microgenética.

\section{Metodologia}

\subsection{Objetivos e caracterização dos participantes}

No estudo da planificação durante a passagem de turno foram definidos três objetivos específicos:

- Caracterizar a atividade de planificação das ações prescritas e não prescritas, propondo uma grelha para a sua análise;

26 - Compreender o papel da antiguidade no Serviço e dos conhecimentos na planificação da ação prescrita e não prescrita;

27 - Compreender o papel da antiguidade no Serviço e da incerteza na atividade de planificação das ações não prescritas.

28 A escolha de um Serviço de Cirurgia Geral deveu-se à possibilidade de conciliar a recolha de dados com os nossos objetivos; o que exigia, principalmente:

29 - a disponibilidade dos enfermeiros para participarem na recolha de dados - a sua autorização para a realização de observações do trabalho em contexto real, para a prestação de esclarecimentos e informações sobre a atividade observada e para a realização de entrevistas sobre a passagem de turno;

30 - a autorização de todos os elementos da equipa de saúde do Serviço, enfermeiros, médicos e auxiliares de ação médica, para a realização das gravações audiovisuais da passagem de turno;

31 - a autorização do Hospital para a nossa permanência na instituição, para a gravação audiovisual do trabalho de enfermagem em contexto real e para a consulta de documentos e informações sobre os doentes.

32 No conjunto dos 21 enfermeiros do Serviço de Cirurgia Geral, participaram voluntariamente na realização da simulação da passagem de turno e das entrevistas nove enfermeiros. A escolha dos nove enfermeiros deveu-se, simultaneamente, a dois critérios:

33 - a experiência profissional no serviço, de acordo com a antiguidade no Serviço;

34 - a participação na respetiva passagem de turno real.

35 A antiguidade no Serviço

36 A antiguidade foi considerada constituindo-se três classes de antiguidade com três enfermeiros cada:

A - experiência de trabalho no Serviço entre um ano e sete meses e quatro anos e cinco meses, formação no nível do bacharelato e categoria profissional enfermeiro

B - experiência de trabalho no Serviço entre cinco anos e seis meses e dez anos e um mês, formação ao nível do bacharelato e na categoria profissional enfermeiro

39 C- experiência de trabalho no Serviço entre dez anos e dez meses e treze anos e seis meses; no conjunto dos três enfermeiros pertencentes a esta classe de antiguidade, dois 
têm uma formação ao nível do bacharelato e um enfermeiro possui a licenciatura em enfermagem; os três situam-se na categoria profissional de enfermeiro graduado.

Escolhemos agrupar os enfermeiros em três classes de antiguidade com o objetivo de caracterizar um momento intermédio do seu percurso profissional, durante o qual podem ocorrer acontecimentos distintos dos que caraterizam o início e as fases mais tardias deste percurso. Por outro lado, procuramos, no conjunto dos vinte e um enfermeiros, incluir em cada classe de antiguidade, o mesmo numero de enfermeiros com antiguidades no Serviço e na Instituição próximas e, simultaneamente, mais distantes relativamente à(s) classe(s) de antiguidade anterior(es) e seguinte(s). Considerando as características da antiguidade no Serviço e na Instituição no conjunto dos enfermeiros do Serviço, este último critério foi atingido apenas parcialmente.

A participação na passagem de turno real

Para a realização da passagem de turno simulada e entrevistas, escolhemos enfermeiros que não participaram na passagem de turno real, correspondente. Uma vez que pretendíamos comparar enfermeiros de acordo com a sua experiência profissional no serviço, a informação deveria ser igual para todos os enfermeiros que participaram na passagem de turno simulada e, por isso, estes deveriam ser confrontados com a mesma situação de trabalho. Assim, as informações orais e outras, recolhidas e retidas, relativas à atividade realizada em turnos imediatamente anteriores à passagem de turno, fundamentais na procura de informação, nas interpretações que realiza e nas decisões que o enfermeiro toma durante a passagem de turno, deveriam ser controladas. Por isso, para além dos casos dos doentes terem sido iguais para cada uma das classes de antiguidade (o mesmo número de doentes, diagnósticos e os seus estados no momento da passagem de turno) procuramos, também, que a informação oral e retida sobre a atividade, nos turnos imediatamente anteriores e posteriores à passagem de turno real, fosse igual para todos os enfermeiros. Distanciamos, por isso, no tempo as passagens de turno reais e a sua simulação (a passagem de turno simulada foi realizada um mês após a realização da correspondente passagem de turno real) e escolhemos enfermeiros que não haviam participado na passagem de turno real. Consideramos que, desta forma, os enfermeiros dispunham da mesma informação escrita disponível, no momento da passagem de turno simulada, e a informação não escrita, sobre aspetos específicos dos doentes ou das situações de trabalho nos turnos imediatamente anteriores ou posteriores à passagem de turno real, não seria recordada pelo enfermeiro, durante a passagem de turno simulada, uma vez que este não havia participado na passagem de turno real.

Para cada um dos enfermeiros a simulação realizou-se com base numa passagem de turno real (manhã ou tarde ou noite) e a entrevista conceptual baseou-se na apresentação de informação relativa, somente, a três casos de doentes apresentados nessa passagem de turno real.

No quadro 1 apresentamos a distribuição dos enfermeiros das três classes de antiguidade pelas três passagens de turno e pelos doentes apresentados. 
Quadro 1 - Distribuição dos enfermeiros das três classes de antiguidade, pelas três passagens de turno e pelos nove doentes

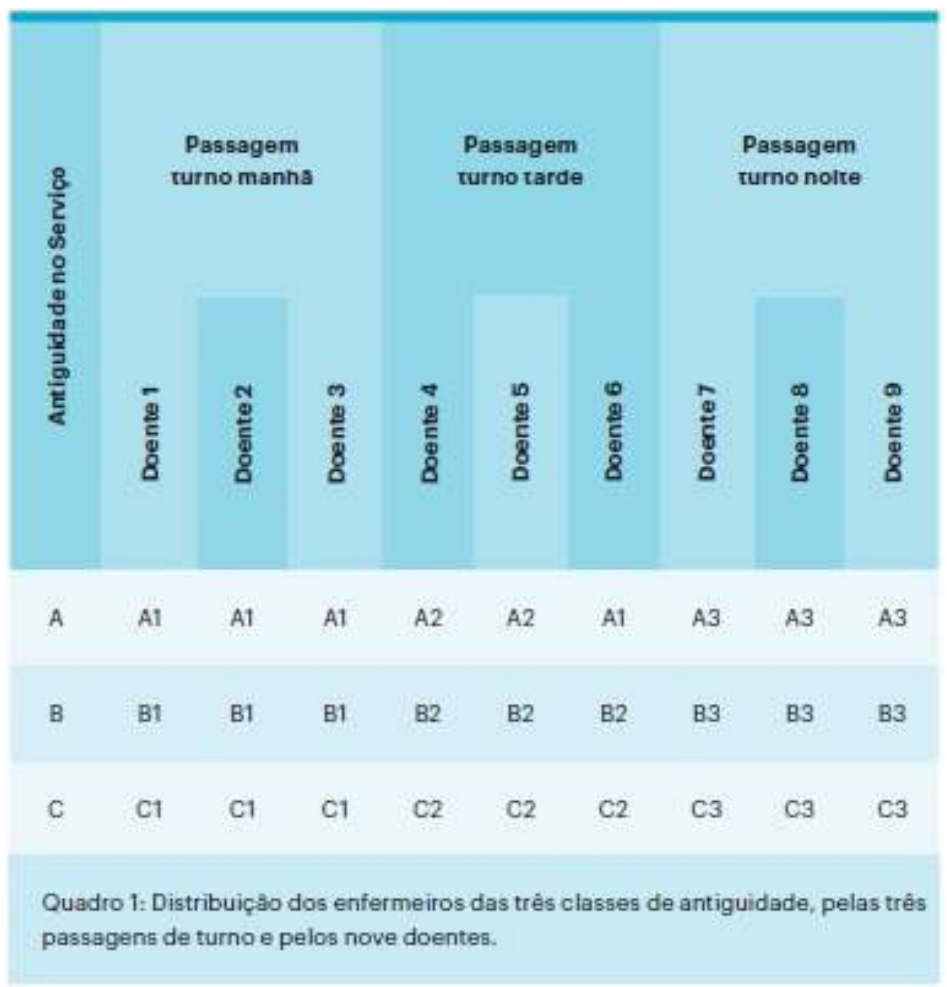

Como podemos constatar através da observação do Quadro 1 , cada uma das classes de antiguidade, A, B ou C, é constituída por três enfermeiros. Um enfermeiro da classe A, B e C (A1, B1 e C1, respetivamente) participou na simulação da passagem de turno da manhã, um enfermeiro da classe A, B e C (A2, B2 e C2, respetivamente) na passagem de turno da tarde e um terceiro enfermeiro da classe A, B e C (A3, B3 e C3, respetivamente) na passagem de turno da noite. Outro elemento a salientar é a distribuição dos enfermeiros, das três classes de antiguidade, pelos casos dos doentes: um enfermeiro da classe A, um enfermeiro da classe B e um enfermeiro da classe C realizaram a planificação da atividade relativa aos mesmos três doentes. Como mencionamos, desta forma procuramos controlar, mantendo iguais nas três classes de antiguidade, possíveis efeitos relacionados com especificidade da patologia de cada doente e do conteúdo do trabalho nos três turnos que, embora fundamentais na organização da ação, não foram analisados neste estudo.

\subsection{A simulação da passagem de turno e a entrevista conceptual}

Os resultados que apresentamos no ponto 6 foram recolhidos num contexto que procurou reproduzir uma passagem de turno real. Esta opção deveu-se ao fato de não ser possível realizar entrevistas aos enfermeiros durante o período da uma passagem de turno real. A simulação da passagem de turno e a entrevista conceptual foram realizadas individualmente, numa sala de trabalho no hospital, durante o tempo de trabalho.

Cada sessão de simulação teve uma duração média de quinze minutos e foi constituída por três momentos: 
48 - inicialmente o investigador pedia ao enfermeiro para se imaginar na passagem de turno real sendo dadas as instruções "Imagine que vai iniciar o trabalho no turno $\mathrm{x}$ (manhã ou tarde ou noite), vou transmitir-lhe informação relativas a 3 doentes que lhe estão atribuídos no plano coletivo de cuidados, agradecia que procedesse como numa passagem de turno real";

49 - num segundo momento o investigador apresentou, individualmente, a cada um dos enfermeiros, toda a informação oral disponível na passagem de turno real (manhã ou tarde ou noite), relativa a três doentes; em simultâneo, alguns enfermeiros registavam a informação que consideravam útil, num bloco de notas, como o faziam habitualmente durante a passagem de turno real;

50 - no final os enfermeiros registaram, no seu bloco de notas, os cuidados a realizar com os seus doentes a partir das informações apresentadas no plano coletivo de cuidados, como é habitual na situação real de passagem de turno.

51 Imediatamente após a simulação, foi realizada, individualmente, a entrevista conceptual com uma duração média de noventa minutos. Nesta entrevista apresentamos a informação que havia sido transmitida oralmente, durante a simulação da passagem de turno, decomposta em enunciados (mais pequena unidade de informação com sentido do ponto de vista da atividade do enfermeiro) e sequências (conjunto de enunciados ligados por uma relação causal ou de conteúdo). Para cada sequência pedimos ao enfermeiro para comentar o que iria fazer com a informação no turno que iria iniciar, pedindo-se para indicar o objetivo de cada uma das ações indicadas e para justificar porque faz aquilo que faz. Sempre que considerasse necessário o enfermeiro podia consultar informação adicional nos documentos disponíveis, devendo indicar as razões da consulta. As questões colocadas foram do tipo:

52 - o que vai fazer com a informação, o que quer dizer com esta informação, o que deduz com a informação:

53 - o que procura quando quer saber determinado valor? Quando vê x e diz que é y como é que sabe isso? Existe ligação entre os dois? Como a explica? Como é que x age sobre y?

54 As questões colocadas não procuraram estabelecer exaustivamente todas as relações possíveis na informação disponível. As relações não foram procuradas pelo investigador, elas surgiam à medida que o enfermeiro centrava a sua atenção sobre um ou outro aspeto do doente, procurando-se a explicitação dos saberes e do raciocínio que o enfermeiro realizava, espontaneamente, sobre os dados do doente.

55 A entrevista foi gravada e transcrita para análise.

\section{Resultados}

\subsection{A grelha de análise da passagem de turno}

56 A grelha de análise proposta constitui uma primeira proposta, por isso exploratória, para o estudo dos saberes, segundo as duas abordagens seguidas (macro e microgenética), devendo ser retrabalhada e melhorada por outras análises, a realizar em estudos futuros.

57 De acordo com a perspetiva macrogenética, a planificação das ações durante a passagem de turno é um modo de controlo da ação através da conceptualização ao 
longo da vida profissional. O contexto de trabalho, os outros, as normas da instituição, os protocolos e as prescrições são fundamentais no trabalho de conceptualização. Assim, procuramos compreender o papel particular da experiência (antiguidade no Serviço) e dos conhecimentos na planificação da ação prescrita (regras institucionais, prescrições médicas, protocolos) e não prescrita (ações autónomas do enfermeiro). Identificamos objetivos do enfermeiro para o turno que vai iniciar, ações (regras de ação prescritas e não prescritas) e as suas justificações (regras de compreensão). 0 plano de ação é constituído por:

- objetivos, por exemplo "vigiar heparinização"; - ações (regras de ação), por exemplo "se heparina vigiar o local da punção";

- explicação das ações (regras de compreensão - justificações, explicações, motivos, razões); na explicação da ação encontramos catorze tipos de conhecimentos; por exemplo, a enfermeira explica porque é importante vigiar uma doente com isquemia e verificar a fórmula leucocitária: "a doente pode ter uma infeção e nesse caso estes valores estão todos alterados, vai haver libertação de toxinas, começa a ficar naquele quadro de uma sepsis, a doente começa a ficar desorientada e pode morrer"

De acordo com a perspetiva microgenética procuramos caracterizar a atividade de planificação da ação nas situações prescritas e não prescritas. Estudamos esta atividade identificando, para além dos objetivos, ações, e justificações (tal como na perspetiva macrogenética), as fontes da informação e o tipo de alternativas que o enfermeiro propõe. Procuramos, assim, abordar a conceptualização da ação do ponto de vista da extensão dos saberes em termos espaciais, temporais e dos possíveis (Piaget, 1978).

$\mathrm{Na}$ explicação da atividade de planificação, o enfermeiro centra-se em determinados dados sobre o doente (sintomas físicos, reações psicológicas, diagnósticos médicos, zonas anatómicas, ações e procedimentos realizados, etc.), recolhidos junto de diferentes fontes de informação (documentos escritos, transmitidos oralmente). As explicações são relações entre estes dados explicitando diferentes tipos de saberes (condições fisiológicas - por exemplo, a circulação nas artérias obstruídas; vigilância no tempo; comparações com uma norma - por exemplo, um número, uma média aritmética ou uma relação entre dois valores do tipo acima, abaixo, maior, menor, por exemplo a relação sódio potássio) sob determinadas formas. As fontes de informação e a forma como os saberes são explicitados são associados à incerteza. Assim, analisamos os dados considerando a sua fonte: registados, nos documentos escritos disponíveis durante a passagem de turno ou transmitidos oralmente; não registados em qualquer documento escrito e não transmitidos oralmente. No primeiro caso, os dados são constatados pelo enfermeiro enquanto que no segundo caso eles são, apenas, representados mentalmente, existindo uma maior distância relativamente aos dados concretos e uma maior incerteza relativamente à sua ocorrência - extensão espacial.

Do ponto de vista da forma analisamos as relações estabelecidas entre os dados do doente, os saberes, considerando a existência de alternativas e o tempo. No que se refere às alternativas, os saberes podem ser explicitados sob a forma de hipóteses e, neste caso, temos relações incertas; ou, pelo contrário, são estabelecidas relações sob a forma de identificações e, neste caso, são relações certas; o enfermeiro não exprime qualquer dúvida sobre a sua relação. A distinção entre o estabelecimento de relaçães certas e incertas é marcada pela possibilidade de coordenar simultaneamente diferentes perspetivas sobre a situação. Se as relações são certas, identificações, não 
existem alternativas na situação; se, pelo contrário, as relações são incertas, hipóteses, outras alternativas podem existir na situação - extensão dos possíveis.

Estudamos, também, os saberes explicitados no estabelecimento das relações entre os dados considerando-os do ponto de vista temporal. Os conhecimentos podem supor uma relação temporal entre dados ou uma relação não temporal. No primeiro caso existe vigilância, no tempo, da evolução da situação (comparação de um sinal ao longo do tempo) ou uma previsão, no presente, de cenários futuros (previsão causal); contrariamente ao que acontece nas relações temporais, nas quais existe incerteza, nas relações não temporais a ação é decidida imediatamente, sem incerteza relativamente à ação a realizar. Mas, nos dois tipos de relações temporais, a incerteza não é da mesma natureza porque o tempo tem um conteúdo com características distintas nas duas situações. Por vezes, o tempo supõe uma atividade de vigilância da evolução da situação (comparação de um sinal ao longo do tempo), noutras situações indica uma atividade de representação da relação no tempo (previsão causal). A representação da relação no tempo obriga o enfermeiro a inferir o efeito de uma ação. Neste caso a relação temporal é, do ponto de vista cognitivo, distante das situações concretas de trabalho apoiando-se num modelo simples de pensamento causa-efeito. Mas quando comparada esta relação com as relações temporais não causais, atividade de vigilância da evolução da situação, estas últimas parecem-nos mais complexas uma vez que, e apesar de partirem da observação direta das situações, implicam não só relações de causa efeito como também observação da combinação de diferentes efeitos, a sua avaliação no tempo e a sua integração com outros elementos da situação que podem, entretanto, ser alterados. Neste último caso a incerteza parece aumentar.

Assim, consideramos que a explicação da ação com base em dados não registados nos documentos do doente, sobre os quais são estabelecidas relações hipotéticas e baseadas em conhecimentos temporais não causais traduzem uma maior abstração, a sua extensão do ponto de vista espacial, temporal e dos possíveis e, em consequência, a integração da incerteza na ação. A combinação das diferentes possibilidades dos três critérios considerados origina doze formas de explicar a ação caracterizadas por diferentes tipos e graus de incerteza. Obtivemos, assim, uma escala com sete níveis de incerteza que caracterizam sete registos na explicação da ação, sete registos de funcionamento, apresentados no quadro 2 . 
Quadro 2 - Caracterização dos sete registos de funcionamento

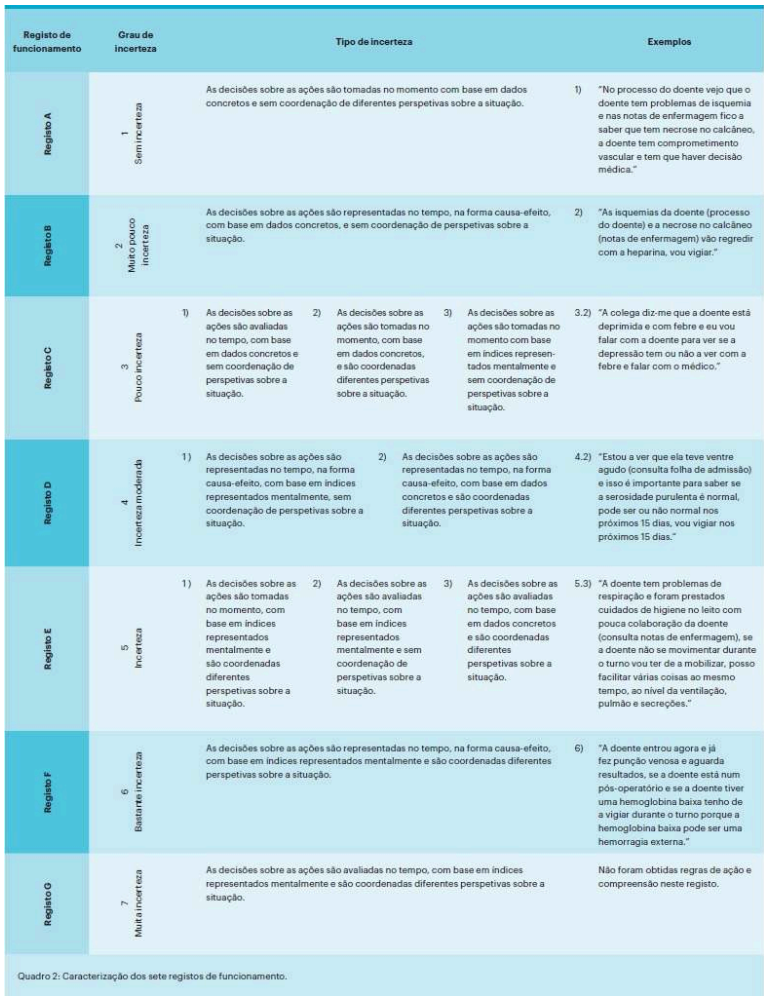

66 As características da explicação da ação analisadas com base nestes critérios (extensão temporal, espacial e dos possíveis) traduzem, de acordo com a proposta de Piaget (1978) e Vermesch (1978), a estabilidade das respostas, a possibilidade de anular as perturbações integrando-as no esquema de ação, a resistência às perturbações (WeillFassina, 2010), característica dos trabalhadores mais experientes. Foi esta análise exploratória que efetuamos por classe de antiguidade (6.3.).

\subsection{A antiguidade no serviço e os conhecimentos utilizados na explicação da ação prescrita e não prescrita}

O número de regras de ação prescritas explicadas (RAPE), regras de ação não prescritas explicadas (RANPE), regras de ação prescritas não explicadas (RAPNE) e regras de ação não prescritas não explicadas (RANPNE) nas três classes de antiguidade é apresentado no gráfico 1 . 
Gráfico 1 - Distribuição das frequências absolutas das regras de ação prescritas explicadas (RAPE), regras de ação prescritas não explicadas (RAPNE), regras de ação não prescritas explicadas (RANPE) e regras de ação não prescritas não explicadas (RANPNE) nas três classes de antiguidade

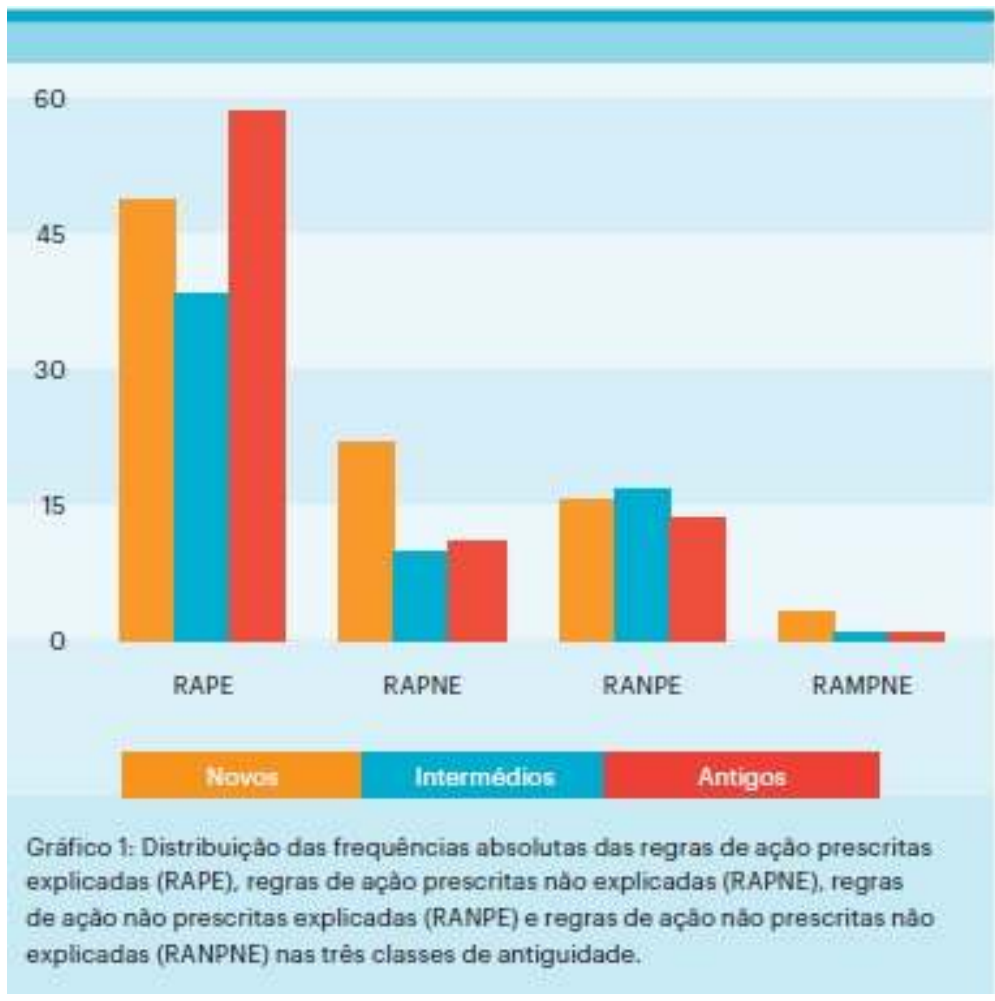

Na observação do gráfico 1 constata-se que no total são formuladas 231 regras de ação. $\mathrm{Na}$ atividade do enfermeiro, as RAP assumem um papel mais importante do que as RANP, o que indica que a atividade é guiada com base em prescrições médicas, protocolos e regras da instituição. 
Gráfico 2 - Distribuição da frequência absoluta das regras de ação prescrita pelas diferentes classes de antiguidade e pelos diferentes tipos de conhecimentos usados para as justificar (comp norma - comparação de um valor com uma norma; comp tempo - comparação de um valor ao longo do tempo; correlação; associação; função; previsão causal; cond fisiol - condições fisiológicas; explicação causal; freq - frequência; local - localização; discre - discrepância; transf - transformação; mater - materialização)

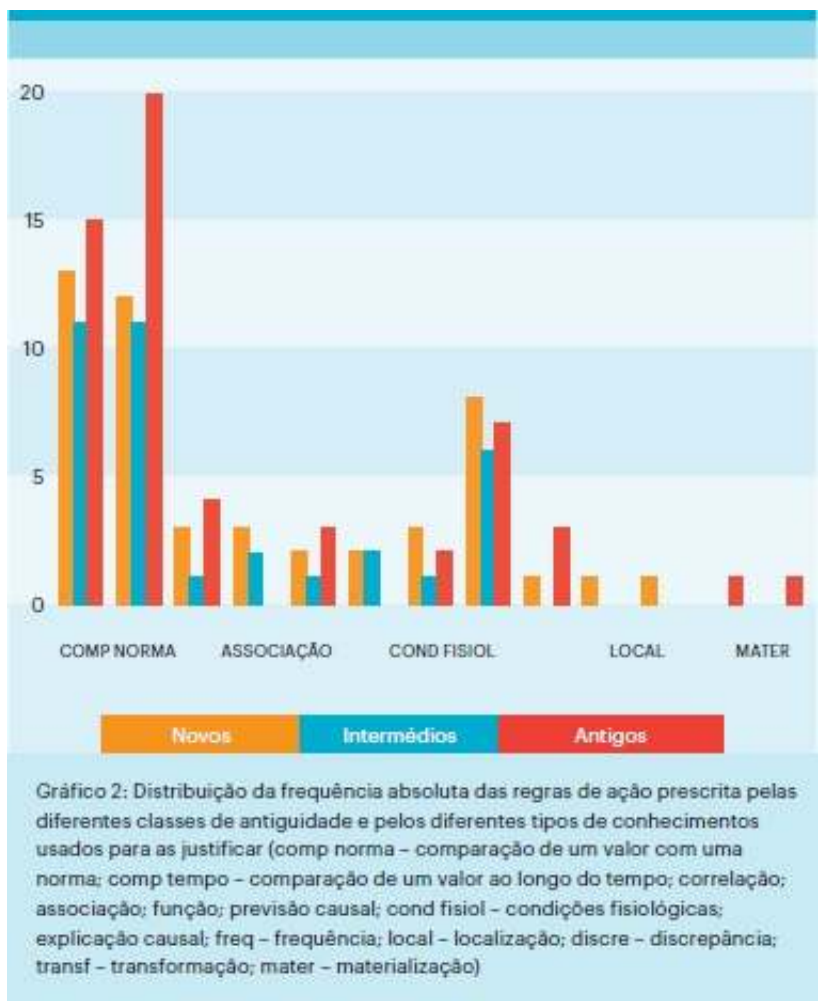

Relativamente às RAP, a comparação com uma norma, a comparação no tempo e a explicação causal são os saberes mais utilizados em qualquer classe de antiguidade, como podemos constatar no gráfico 2. De salientar que a comparação no tempo é o conhecimento mais utilizado pelos enfermeiros mais antigos no serviço e também aquele sobre o qual existe uma maior distinção entre, por um lado, os enfermeiros mais novos e intermédios e, por outro lado, os enfermeiros mais antigos. Estes dados parecem indicar que os enfermeiros mais antigos planeiam vigiar, mais do que os outros, no tempo a evolução da situação do doente. No caso dos enfermeiros da classe intermédia e os mais novos, a comparação no tempo também é uma estratégia indicada para o turno mas estes enfermeiros estabelecem, de igual modo, comparações de um valor com uma norma. Na comparação de um valor com uma norma o enfermeiro evoca um número, uma média aritmética ou uma relação entre variáveis específicas do doente para julgar, numa situação, um valor acima, abaixo, normal, não normal, elevado, etc. (por exemplo, a relação entre o sódio e o potássio), para agir. Neste caso coordena conceptualmente os dados que são apresentados e julga-os de acordo com uma norma para agir. Para estes enfermeiros, as regras de ação prescrita são observadas no tempo e são também avaliadas. Para os enfermeiros mais antigos as prescrições são, também, avaliadas mas são em maior número observadas durante o turno.

70 Assim, e no que se refere à ação prescrita, salientamos uma evolução, com a antiguidade no Serviço, das estratégias de ação no sentido da observação das situações no tempo, o que pode traduzir um melhor conhecimento dos enfermeiros, mais antigos, 
relativamente às observações a realizar no turno assim como a importância que atribuem à adequação e ajustamento das suas práticas à evolução das situações. Parecenos que estamos perante um maior controlo da ação nos mais antigos.

No que se refere às RANP, podemos observar no gráfico 3 que a comparação no tempo é o conhecimento mais utilizado, na planificação da ação.

Gráfico 3 - Distribuição da frequência absoluta das regras de ação não prescrita pelas diferentes classes de antiguidade e pelos diferentes tipos de conhecimentos usados para as justificar (comp norma - comparação de um valor com uma norma; comp tempo - comparação de um valor ao longo do tempo; correlação; associação; função; previsão causal; cond fisiol - condições fisiológicas; explicação causal)

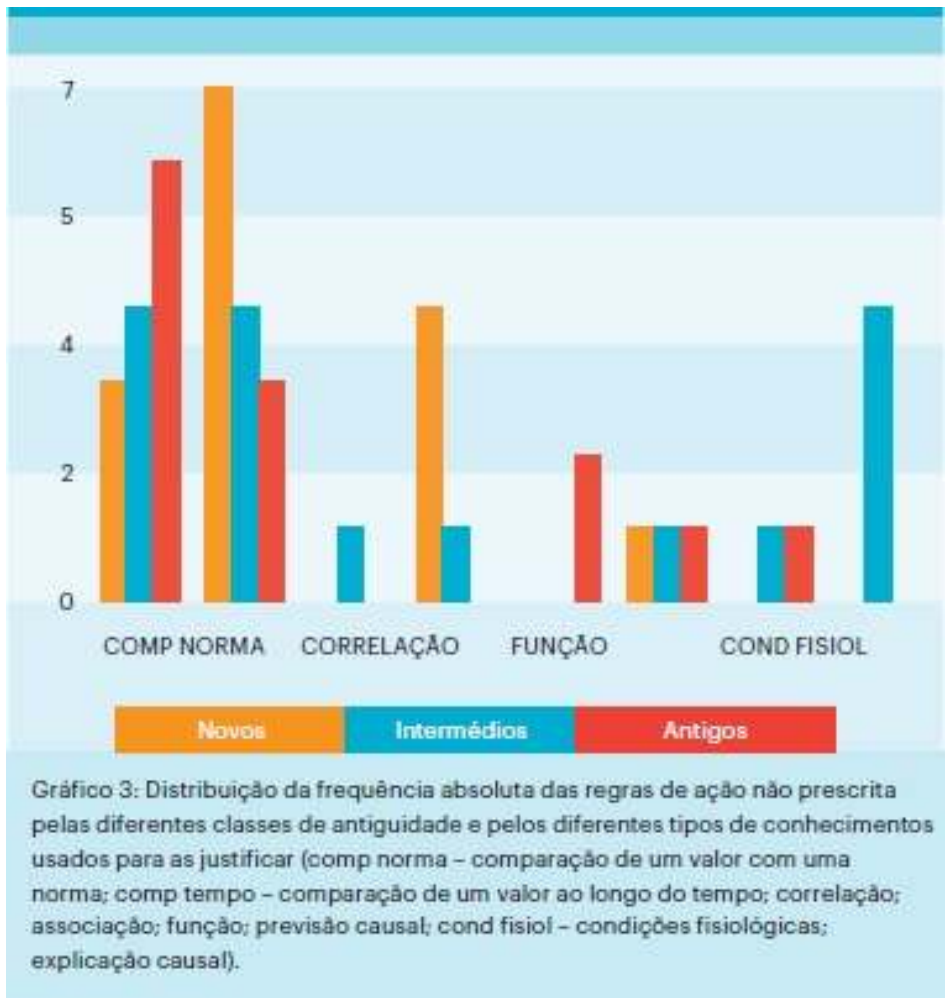

Nos enfermeiros mais novos no Serviço, o conhecimento mais utilizado é a comparação no tempo. Nos enfermeiros intermédios são igualmente utilizados os conhecimentos comparação de um valor com uma norma, comparação no tempo e explicação causal. Este último tipo de conhecimento é, aliás, o que distingue estes enfermeiros dos enfermeiros mais antigos e mais novos, já que os intermédios são os únicos a utilizar a explicação causal na ação não prescrita. Nos enfermeiros mais antigos no serviço, a comparação com uma norma é o conhecimento mais utilizado, sendo de salientar que esta classe de antiguidade é, também, a única que utiliza o conhecimento função para explicar a sua ação.

Na comparação de um sinal ao longo do tempo o enfermeiro planeia observar, no turno, elementos relativos ao doente e ao Serviço. Principalmente nas ações não prescritas, ações para as quais não existem indicações formalizadas devendo o enfermeiro tomar as decisões de forma autónoma e agir, a planificação da ação deveria traduzir-se por uma maior preparação destas ações de observação. Assim sendo, a planificação da atividade incluiria um maior número de observações a realizar junto do doente (comparação no tempo) se comparada com a ação prescrita. Os resultados obtidos, 
relativos aos enfermeiros das três classes de antiguidade, não indicam esta maior preparação da ação não prescrita e consideramos, por isso, no caso da ação não prescrita, que a vigilância de um sinal ao longo do tempo indica uma estratégia passiva no tempo "esperar para ver". Estes resultados estão de acordo com análises de atividades de serviços. Degoulet (2015) salienta que os menos experientes dedicam pouco tempo à preparação da ação futura, à antecipação de imprevistos e problemas que ocorrem durante o trabalho. Nos enfermeiros mais antigos no Serviço, a ação caracteriza-se pela coordenação de vários elementos da situação, para estabelecer uma norma e agir (comp norma) como também se caracteriza pelo pragmatismo (função), a ação é um meio de diagnóstico e intervenção. Por exemplo, o doente está na cama e é não colaborante, o enfermeiro durante o turno vai posicionar o doente para aliviar as zonas de pressão. Nos enfermeiros da classe intermédia, a ação carateriza-se por uma estratégia compreensiva já que existe uma avaliação causal, o estabelecimento de uma explicação causa-efeito (A é a causa de B ocorrer), num determinado momento, para agir. Neste caso, a coordenação conceptual entre elementos da situação refere-se a uma relação simples de causa e efeito.

Propomos, assim, três tipos de estratégia para caracterizar a ação não prescrita do enfermeiro: a estratégia passiva, a estratégia ativa e pragmática. Os três tipos de estratégia sugerem que, com a experiência profissional, existe transformação da ação não prescrita no sentido de um maior controlo das situações.

A comparação das estratégias de ação prescrita e estratégias de ação não prescrita sugere que a prescrição da ação não parece influenciar o desenvolvimento da atividade ao longo da vida profissional. Nas três classes de antiguidade, salientamos as características da ação não prescrita e prescrita nos enfermeiros mais antigos. Ambas parecem traduzir um maior controlo das situações, prescritas e não prescritas, por parte dos enfermeiros mais antigos.

\subsection{A antiguidade no serviço e a incerteza na planificação da ação não prescrita}

Analisamos as regras de compreensão segundo critérios que consideramos indicadores da sua extensão temporal, espacial e dos possíveis, conforme 6.1.obtivemos frequências em seis dos sete registos possíveis, como podemos constatar no gráfico 4 . 
Gráfico 4 - Distribuição das frequências absolutas dos seis registos de funcionamento pelas três classes de antiguidade

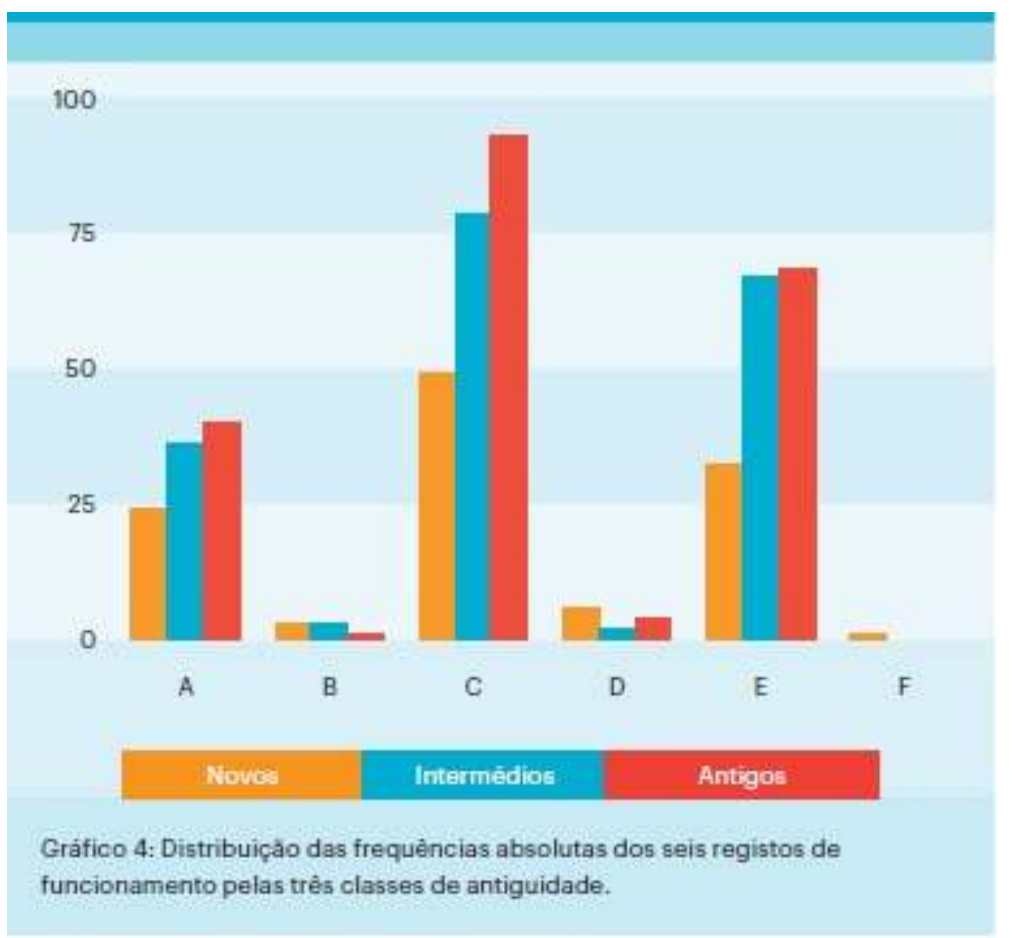

Os registos de funcionamento mais frequentes em qualquer classe de antiguidade são o registo $\mathrm{C}$ e o $\mathrm{E}$, apresentando cada um três formas alternativas, como podemos constatar no Quadro 2. Comparando as frequências dos dois registos, verifica-se que o registo $C$ é o mais frequente, em qualquer classe de antiguidade.

Comparando as características das três alternativas do registo de funcionamento $\mathrm{C}$ com as características das três alternativas do registo $\mathrm{E}$ (Quadro 2), constata-se que o registo E é ligado a uma maior incerteza sobre o que fazer e sobre os dados do doente. $O$ enfermeiro dirige mais a sua atenção para elementos não constatados junto do doente, apenas representados mentalmente e, considerando a situação do doente, ele interroga-se sobre outras alternativas. No entanto, parece-nos que a incerteza se associa a uma maior prudência já que dadas as características do trabalho do enfermeiro, ação exercida sobre o doente em circunstâncias que evoluem continuamente e sobre as quais não existe um completo controlo, esta forma de planear a sua ação integra a imprevisibilidade da situação sendo por isso mais realista e, deste modo, talvez mais adaptada e segura.

$O$ registo de funcionamento $\mathrm{E}$, apesar de menos frequente do que o registo $\mathrm{C}$ em qualquer classe de antiguidade, é mais frequente nos mais antigos e nos enfermeiros da classe intermédia, sugerindo que, com a experiência profissional, há integração da imprevisibilidade da situação na atividade de planificação.

\subsection{As estratégias e a imprevisibilidade da ação}

O conhecimento é organizado para a ação de acordo com diferentes conhecimentos que correspondem a diferentes formas de planear a ação para o turno relacionadas, obviamente, com as características dos doentes, do turno de trabalho mas também com a experiência profissional do enfermeiro. Assim, a comparação da planificação da ação 
nas três classes de antiguidade sugere que a experiência do enfermeiro proporciona o confronto com situações de trabalho que favorecem a ação mais adaptada a um contexto. A experiência profissional parece, também, proporcionar uma maior "resistência às perturbações" uma vez que o enfermeiro mais experiente integra, mais do que o menos experiente, a imprevisibilidade das situações na atividade de planificação que realiza. Neste sentido, a experiência de trabalho favorece o desenvolvimento de competências de gestão da imprevisibilidade na prestação de cuidados.

\section{Conclusão}

81 A descrição do trabalho, o quadro teórico e a metodologia que orientaram a nossa explicação da forma como o enfermeiro gere os múltiplos constrangimentos da sua atividade (objetivos próprios, objetivos da organização, recursos materiais, recursos humanos, regras) e desenvolve competências não pretende ter o valor de prova, o seu principal contributo é abrir o debate sobre o trabalho e propor a vários intervenientes, no mundo do trabalho, uma abordagem que salienta os fatores humanos na sua realização. Esta tentativa exploratória de aproximação à atividade do enfermeiro deve ser continuada pelo aprofundamento de várias questões que deixamos em aberto e pela análise de outras situações de trabalho.

82 A situação de trabalho escolhida para a análise foi definida como uma tarefa de planificação, tendo sido identificados, pelos enfermeiros, objetivos e meios para os atingir. Assim, foi possível ultrapassar uma análise técnica do trabalho do enfermeiro complementando-a com uma análise psicológica. Esta última permitiu identificar ações realmente praticadas, as estratégias planeadas para o turno, os recursos utilizados, as relações que os enfermeiros estabelecem entre diferentes elementos que caraterizam o seu ambiente de trabalho, as prioridades que estabelecem. A análise psicológica do trabalho e o quadro teórico no qual nos apoiamos também tornou possível uma primeira proposta de registos de funcionamento, formas de lidar com a incerteza característica do trabalho do enfermeiro.

$\mathrm{Na}$ análise do trabalho salientamos os seus aspetos sociais, a partilha de recursos e a construção em comum, ao longo da vida profissional, de ações, regras, linguagens, e a sua influência na conceptualização da prestação de cuidados. Mas os aspetos do trabalho coletivo do enfermeiro são fundamentais, a dependência relativamente aos enfermeiros de outros turnos e a outros profissionais da equipa de saúde para serem atingidos objetivos comuns na realização do trabalho. Assim, o nosso estudo deverá ser continuado no sentido de um maior aprofundamento dos aspetos sociais e, principalmente, dos aspetos coletivos insuficientemente abordados.

84 No plano coletivo parecem-nos importantes questões sobre como é que um mesmo objetivo é atingido por vários enfermeiros? Que tipo de interação se estabelece entre eles? Como é que ela se desenvolve ao longo da vida profissional? Como favorecer esta cooperação? Como favorecer a cooperação entre serviços? Estes aspetos, fundamentais no desenvolvimento das competências, são praticamente inexistentes durante a passagem de turno e, por isso, a continuação do estudo obriga a uma reformulação das condições e situações de recolha de dados. 
No plano social, os aspetos sociais do trabalho foram reduzidos a uma análise por classe de antiguidade supondo-se que a antiguidade no Serviço seria um indicador da conceptualização, realizada ao longo da vida profissional, na interação com o contexto social de trabalho. Assim, também consideramos fundamental o aprofundamento das conclusões que retiramos por classe de antiguidade. As análises individuais, estabelecendo comparações e distinções entre enfermeiros, com características de formação e experiências diversas, em substituição da análise por classes de antiguidade, são mais adequadas ao estudo que iniciamos. Cada enfermeiro é um caso singular que pode ser situado no conjunto de outros enfermeiros em função de características que, no nosso estudo, se reduziram à experiência de trabalho no serviço. A retenção destes indicadores é com certeza muito redutora da realidade, negligenciando, ainda que de forma provisória, diferenças fundamentais na explicação da ação: a formação específica do enfermeiro, as suas experiências, as características dos doentes e dos turnos de trabalho. A ação analisada é a ação explicitável, a ação também pode não ser explicada. Como Montmollin (1996) salienta existem situações de trabalho nas quais a emoção e a empatia são mais importantes do que os saberes na explicação da atividade e esta é, seguramente, uma dimensão importante na atividade do enfermeiro que, em diversas situações tem, simplesmente, como objetivo "fazer o doente sorrir". o significado da atividade não se reduz ao tratamento de informação, quer esta seja pré-determinada ou construída em situação (Pinsky \& Theureau, 1982; Weill-Fassina, 1993). Como muitos estudos sobre a carga psíquica dos enfermeiros o demonstram (Benner, 1987; Malchaire, 1992), o significado é também a gestão de sentimentos e de emoções fundamentais no controlo da ação. Assim, estudos futuros deverão contemplar a dimensão experiencial da atividade (Schwartz, 2011), na qual é fundamental considerar a articulação corpo-mente na ação humana, sobre os objetos e sobre os outros, num determinado contexto. O conceito de corps-soi, proposto por Schwartz (2011), é fundamental nesta análise.

Apesar da especificidade do nosso estudo e do seu carácter exploratório, constatamos a variabilidade de estratégias e a sua transformação ao longo da vida profissional o que sugere o interesse em alargar o estudo a outras populações de enfermeiros na realização de outras tarefas noutros contextos de trabalho em situação de cooperação. A continuação deste tipo de estudos possibilitará, com certeza, a recolha de outros dados que permitirão complementar e ampliar a nossa compreensão sobre a variabilidade e o desenvolvimento de competências.

\section{BIBLIOGRAFIA}

Benner, P. (1987). Práctica progresiva en enfermería. Manual de comportamiento profesional. Barcelona: Ediciones Grijalbo.

Cahour, B., \& Salembier, P. (1995). Cooperation \& cooperator modeling. Proceedings of the Institut National de Recherche en Informatique et en Automatique, 187-202. 
Clot, Y. (1995). Le Travail sans l'Homme? Pour une Psychologie des milieux de travail et de vie. Paris: Éditions La Découverte.

Delgoulet., C. (2015). Novato?. Laboreal, 11(2).

Falzon, P. (1989). Ergonomie cognitive du dialogue. Grenoble: Presses Universitaires de Grenoble.

Fischer, K. W., \& Bidell T. R. (2006). Dynamic development of action, thought and emotion. In W. Damon, \& R. M. Lerner (Eds.), Theoretical models of human development. Handbook of child psychology, (pp. 313-399). New York: Wiley.

Grusenmyer. C. (1996). De l'analyse des communications à celle des représentations fonctionnelles partagées. Une application à la relève de poste. INRS, Service Ergonomie et Psychologie Industrielle, Paris.

Hoc, J.M. (1996). Supervision et contrôle de processus, la cognition en situation dynamique. Grenoble: PUG.

Malchaire, J. (1992). Evaluation de la charge de travail des infirmières. In M. Estryn-Behar, C. Gadbois, \& M. Pottier (Coord.), Colloque International Ergonomie à l'Hôpital (pp. 217-221). Paris: Octares Editions.

Montmollin, M. (1996). Savoir travailler. Le point de vue de l'ergonome. In J. M. Barbier (Dir.), Savoirs théoriques et savoirs d'action (pp. 189-199). Paris: PUF.

Pastré, P. (2007). Activité et apprentissage en didactique professionnelle. In M. Durand \& M. Fabre (Eds.), Les situations de formation entre savoirs, problèmes et activité (pp. 103-121). Paris: L'Harmattan.

Pastré, P. (2011). La didactique professionnelle, approche anthropologique du développement des adultes. Paris: Presses Universitaires de France.

Piaget, J. (1975). L'équilibration des structures cognitive, problème central du développement. Paris: PUF.

Piaget, J. (1978). Introduction. Recherches sur la généralisation. Paris: PUF.

Pinsky, L., \& Theureau, J. (1982). Activité cognitive et action dans le travail. Paris: CNAM.

Roussel, J. F. (2011). Le transfert des apprentissages en milieu organisationnel: réflexions, perspectives et nouvelle taxonomie. Travail et Apprentissages, 8, 11-29.

Rogalski, J. (1994). Formation aux activités collectives. Le Travail Humain, 57(4), 367-386.

Savoyant, A. (1984). Définition et voies d'analyse de l'activité collective des équipes de travail. Cahiers de Psychologie Cognitive, 4(3), 273-284.

Searle, J. R. (1979). Expression and meaning-studies in the theory of speech acts. Cambridge: Cambridge University Press.

Schwartz, Y. (2011). Pourquoi le concept de corps-soi? Corps-soi, activité, expérience. Travail et Apprentissages, 7, 148-177.

Strauss, A., Schatzman, L., Bucher, R., Ehrlich, D., \& Sabshin, M. (1992). L'Hôpital et son ordre négocié. In I. Baszanger (Org.), La trama de la négociation. Sociologie qualitative et interactionnisme (pp. 87-112). Paris: L'Harmattan.

Samurçay, R. \& Pastré, P. (1998). L'ergonomie et la didactique, l'émergence d'un nouveau champ de recherche: didactique professionnelle. Deuxièmes Journées Recherche et Ergonomie. Toulouse, France 
Vermesch, P. (1978). Une problématique théorique en Psychologie du Travail, essais d'application des théories de J. Piaget à l'analyse du fonctionnement cognitif de l'adulte. Le Travail Humain, 41(2), 265-278.

Vygotsky, L.S. (1996). Pensamento e Linguagem (6ª Edição). São Paulo: Martins Fontes.

Weill-Fassina, A. (1993). Introduction. In A. Weill-Fassina, P. Rabardel, \& D. Dubois (Dir.), Représentations pour l'action (pp. 13-27). Toulouse: Octares Éditions.

Weill-Fassina, A. (2010). Evolutions de la gestion de la sécurité en situation de travail avec l'expérience professionnelle. Report $n 58$. Paris: CREAPT-CEE.

\section{RESUMOS}

Do ponto de vista teórico, o objetivo do nosso artigo é refletir sobre o desenvolvimento de competências em contexto de trabalho partindo do estudo da atividade humana e da sua organização conceptual num contexto social. Salientamos duas características da atividade: a variabilidade e o desenvolvimento. Partimos deste quadro teórico para problematizar a planificação da prática dos cuidados de enfermagem no contexto da passagem de turno. A planificação é uma atividade de conceptualização, adaptação constante a um contexto específico, elaboração e reelaboração de conceitos, regras, ações passadas, no contexto atual. A atividade de planificação sendo situada, num contexto específico, e construtiva favorece o desenvolvimento da abstração. Propomos uma formalização do desenvolvimento da abstração articulando a perspetiva macrogenética e microgenética da atividade de planificação, estudada em situação de simulação da passagem de turno real e seguida pela realização da entrevista conceptual.

En lo que respecta a la parte teórica, el objetivo de nuestro artículo es reflexionar sobre el desarrollo de habilidades en el contexto laboral partiendo del estudio de la actividad del hombre y de su organización conceptual en un contexto social. Ponemos especial énfasis en dos características de actividad: en la variabilidad y en el desarrollo. La planificación es una actividad de conceptualización, adaptación contante en un contexto especifico, elaboración y reelaboración de conceptos, reglas y acciones pasadas, en el contexto actual. La actividad de planificación, que se queda en un contexto especifico, y constructiva favorece al desarrollo de abstracción. Proponemos una formalización del desarrollo de la abstracción haciendo una articulación entre la perspectiva macro y micro genética de la actividad de planificación, estudiada en la situación de pasaje de turno real y seguida por la realización de la entrevista conceptual.

D'un point de vue théorique, cet article propose une réflexion sur le développement de compétences en situation de travail à partir de l'étude de l'activité humaine et de son organisation conceptuelle dans un contexte social. Dans cette étude, deux caractéristiques de l'activité sont mises en relief : la variabilité et le développement. La planification est une activité de conceptualisation, d'adaptation constante à une situation spécifique actuelle, d'élaboration et de réélaboration de concepts, de règles, d'actions passées. Dans la mesure où l'activité de planification est localisée et constructive, elle favorise le développement de l'abstraction. Nous proposons une formalisation du développement de l'abstraction en articulant ce que nous avons nommé les perspectives macro-génétique et micro-génétique de l'activité de planification. Cette dernière est étudiée dans des situations de simulation de relèves de poste et par le biais d'entretiens que nous avons qualifié de « conceptuels». 
In a theoretical point of view, the aim of our article is to reflect about the development of the competences, in a working context, starting from the study of the human activity and its conceptual organization in a social context. We point out two characteristics of activity; the changeable and the development. We start from this theory to question the planning of the practice of the nursing care, in the context of changing shifts. Planning is an activity of conceptualizing, constant adaptation to a specific context, elaborating and elaborating again the concepts, rules, past actions, in a present context. The planning activity placed in a specific context and when constructive, favors the development of abstraction. We suggest a formalization of the abstract development, articulating the macrogenetics and microgenetics of the planning activity, studied in a simulated situation of changing shifts and followed by the realization of a conceptual interview.

\title{
ÍNDICE
}

Mots-clés: compétences, variabilité, développement, soins infirmiers

Palabras claves: habilidad, variabilidad, desarrollo, cuidados de enfermería

Keywords: competences, variability, development, nursing care

Palavras-chave: competências, variabilidade, desenvolvimento, cuidados de enfermagem

\author{
AUTOR \\ ISABEL FREITAS \\ Professora Auxiliar - Faculdade de Psicologia e de Ciências da Educação da Universidade do Porto, \\ Rua Alfredo Ellen, 4200-135, Porto, Portugal \\ freitas@fpce.up.pt
}

